\title{
Avocational Contact Dermatitis-Pearls for Recognition and Management
}

\section{Michael P. Sheehan, MD}

\section{Address}

Indiana University School of Medicine, Indianapolis, IN, USA

Email: mpsheeha@iupui.edu

Published online: 13 October 2015

(C) Springer International Publishing AG 2015

This article is part of the Topical Collection on Contact Dermatitis

Keywords Avocational contact dermatitis - Hobbies - Recreational activities · Avocation

\section{Opinion Statement}

Avoidance is the principle treatment for all types of contact dermatitis. The myriad of potential hobbies and recreational activities can make recognizing and managing avocational contact dermatitis challenging. For this reason, it is important to become familiar with some of the more common irritants and allergens encountered.

\section{Key Points}

1. An avocation is a recreational activity or hobby which may lead to exposure of potential cutaneous irritants and allergens.

2. Many cases of avocational contact dermatitis present as hand dermatitis.

3. Prevention is the best strategy for avocational contact dermatitis.

\section{Introduction}

An avocation is an activity that one engages in as a hobby outside of one's main occupation. For many, these recreational activities serve as an outlet for their true passion and are a pastime performed with frequency. The list of avocational activities is a diverse as we are. There is a virtually infinite list of potential recreational activities and hobbies. Likewise, the potential triggers for irritant and allergic contact dermatitis are similarly diverse. The following manuscript will highlight some useful clinical vignettes and management pearls associated with contact dermatitis in gardeners, carpenters and woodworkers, artists, culinarians, and musicians. 


\section{Gardeners and plant enthusiasts}

Gardening is a popular hobby for many. Contact dermatitis in gardening and plant enthusiasts can be irritant, allergic, or a hybrid of both. The principle contactants include a wide variety of weeds, garden plants, soil, and additives. A significant proportion of implicated weeds belong to the Compositae family of plants [1]. Ragweed, ironweed, cocklebur, sagebrush, burdock, chamomile, tansy, feverfew, and pyrethrum are examples of Compositae plants.

Allergic contact dermatitis (ACD) to Compositae family plants is detected by patch testing to compositae mix $6 \%$ in petrolatum, sesquiterpene lactone (SQL) mix $0.1 \%$ in petrolatum, or parthenolide $3 \mathrm{mcg} / \mathrm{cm}^{2}$ (a SQL). Screening with compositae mix and SQL mix has been reported to detect $90 \%$ of compositae-sensitive individuals [2,3]. The pattern of plant dermatoses is often that of an 'exposed area' dermatitis, namely involving the hands and fingers, forearms, and face. Some cases become more widespread. The dermatitis may be chronic with red thickened skin noted on physical exam. History may note prominent flares during the start of the growing season. It is also important to note that both allergic and photoallergic contact dermatitis to Compositae can be seen.

Poison ivy, poison oak, and poison sumac are members of the Anacardiaceae family of plants and belong to the genus Toxicodendron. Toxicodendron dermatitis deserves particular mention given the notable prevalence. It has been reported that at least $50 \%$ of the adult population in North America is allergic to poison ivy or poison oak [4]. It is not uncommon for patients to present in spring or early summer after cleaning out their garden beds with pruritic linear streaks of papulovesicular dermatitis. Toxicodendron dermatitis may also look urticarial or cellulitic at times. Urushiol is the plant sap which contains the allergenic catechols. It is absorbed rapidly by the skin, and washing with soap and water must occur within 15 min of exposure to prevent dermatitis. Sensitive patients should be educated on recognition and avoidance. The leaflets of the poison ivy and oak plants grow in groups of three. The old adage is "Leaves of three, leave them be!" Airborne exposure may result from burning brush or logs with residual toxicodendron plants. Rubber gloves have been reported to be ineffective in prevention of toxicodendron dermatitis. The catechols in urushiol are soluble in rubber. Heavy-duty vinyl gloves are recommended [5]. Barrier creams containing quaternium-18 bentonite have been shown to provide some protection [6]. Clothing that has been contaminated should be laundered to remove urushiol resins. Herbicides are available to kill toxicodendron species if avoidance is not an option. Cross-reactions may be seen in sensitive individuals to other members of the Anacardiaceae plant family such as mango, Japanese lacquer tree, Brazilian holly, cashew nut, pistachio, ginkgo biloba, Indiana marking nut, and the black varnish tree [5].

Irritant contact dermatitis (ICD) from plants has been well documented [7]. ICD may be mechanical or chemical in nature and represents the majority of contact dermatitis reactions to plants $[8,9]$. Sources of mechanical irritation include plant hairs (trichomes), spines, and thorns. Sources of chemical irritants include calcium oxalate, protoanemonin, isothiocyanates, diterpene esters, bromelain, and alkaloids [7]. Clinically, 
these reactions may range from acute skin necrosis to chronic dermatitis.

Some plant exposures result in such prototypical reactions that particular mention is warranted. Daffodil itch is the result of handling the stems and bulbs of the daffodil (Narcissus spp.) and has been reported to be the most common contact dermatitis among florists [10]. The abundant calcium oxalate within the stem and bulb is the primary driving irritant which results clinically in xerosis, scaling, and fissures of the hands and fingers. Tulip fingers is similar but allergic in nature. Here, flower enthusiasts develop an ACD on the hands and fingers driven by the allergen tulipalin A also known as alpha-methylene-gammabutyro-lactone from the tulip flower [9].

Exposure to chemical hazards is well documented in agriculture workers. Similarly, the gardening enthusiast may utilize various additives such as pesticides to increase yields. Pesticide ingredients such as copper sulfate ethylene oxide can be very irritating to the skin and ICD is commonly reported. Even pesticides reported to be of a low irritation potential such as glyphosphate have been noted to result in ICD [11]. The principle allergens most frequently noted in pesticides are the fungicides such as dithiocarbamates and thiophthalimides. Overall ACD to pesticides appears to be infrequent. A list of patch test concentrations for pesticides and agricultural chemicals has previously been published [12]. The US Environmental Protection Agency has made recommendations to reduce pesticide exposure that include adequate time interval between pesticide application and working and wearing personal protective equipment such as gloves, aprons, footwear, and headgear when using pesticides [4].

Tools should also be considered as a source of ACD. Rubber and metal allergens are the primary culprits to consider.

Woodworking is a popular hobby. Potential contactants in those who enjoy woodworking and carpentry include wood, glues, tools, and oils.

Almost any wood has the potential to cause ICD. Sawdust is a wellrecognized skin irritant [13]. Detailed manuscripts which outline the potential dermatologic consequences of exposure to various wood species have been previously published $[14,15]$. Colophony or rosin is a natural resin residue obtained from the coniferous tree Pinus palustris and from other pine tree species. Additives in treated wood may also result in dermatitis. Historically, creosote (a tar derivative) was found in some treated lumber such as railroad ties and shipyard lumber. Creosote has been reported to cause phototoxic reactions similar to tar smarts. Today, pressure-treated lumber is most often treated with one of the following classes of preservatives: (1) waterborne preservatives, (2) oil-borne preservatives, and (3) creosote-based preservatives. The bulk of pressure-treated lumber used in residential, commercial, or industrial projects is treated with waterborne preservatives. Frequently used waterborne preservatives include the following: chromated copper arsenate (CCA-C), alkaline copper quat (ACQ-C, ACQ-D, ACQ-D carbonate), micronized copper quat (MCQ), copper azole (CA-B and CA-C, $\mu \mathrm{CA}-\mathrm{C}$ ), and sodium borates (SBX/ DOT). These treatments are often referred to by trade names such as Wolmanized Natural Select $^{\mathrm{Tn}}$ (copper azole), Preserve and NatureWood ${ }^{\circledR}$ (ACQ), MicroPro ${ }^{\mathrm{Tw}}$, Smart Sense ${ }^{\mathrm{Tu}}$ (MCQ), and Advance Guard ${ }^{\boxplus}$ (borate). Oil- 
borne preservatives are primarily used in treatment of wood destined for utility poles. Chlorpyrifos/IBPC, copper naphthenate, and pentachlorphenol are examples of oil-borne preservatives. Creosote-treated wood has a limited role in railroad ties and marine timber [16].

Engineered wood products such as medium-density fiberboard (MDF) may also act as a source of irritant or allergic exposure. MDF is denser than plywood. It is manufactured by combining wood fragments together with a wax and resin binder under high temperature and pressure. The binding agents often contain formaldehyde or formaldehyde-based resins such as melamine-formaldehyde resin [17]. Patch testing with formaldehyde $1 \%$ aqueous, melamine formaldehyde resin $7 \%$ petrolatum, and quaternium-15 $1 \%$ petrolatum may be used to screen for suspected allergy to MDF.

It should be remembered that tools frequently used in woodworking may contain the potential metal allergens nickel, cobalt, and chromium. The grips may also be a source of exposure to black rubber antioxidants (containing phenylenediamine derivatives) and neoprene (containing mixed dialkylthioureas and para-tert-butyl-formaldehyde). Exposure to these often results in hand dermatitis. Linden et al. reviewed nickel release from tools on the Swedish market and noted that $27 \%$ of the 565 handheld tools tested with the dimethylglyoxime test (aka nickel spot test) were positive for nickel release [18]. A Danish study also noted that tools are a potential source of nickel dermatitis [19]. A similar detection kit is also available for cobalt using a water-soluble salt of $\alpha$-nitroso- $\beta$-naphthol-disulfonic acid (aka the cobalt spot test).

Wood glue is essential for many carpentry projects. While each brand will have its own unique formulation, some common ingredients include urethane prepolymer, diphenylmethane-diisocyanate, formaldehyde-based preservatives, polyvinyl acetate, and beeswax. Epoxy-based or cyanoacrylate adhesives are also frequently used in woodworking. Table 1 provides a more extensive list of potential allergens to consider in woodworkers.

Management of ICD and ACD in woodworkers should focus on avoiding exposure to the offending agents. Expanded patch testing is helpful to identify allergens which must be avoided. Patch testing with sawdust or shavings should be performed with caution and only to known wood species. Commercially prepared wood extracts are not readily available for patch testing. A method for obtaining extracts for patch testing has previously been published [15]. Work areas should be equipped with effective ventilation and vacuum systems to minimize fumes and dust. Protective clothing, gloves, and masks should be utilized to prevent skin and respiratory exposure to noxious chemicals and potential allergens. Nickel and cobalt spot tests should be used to identify problematic tools in patients allergic to these metals. Duct tape or barrier coatings may be helpful in select cases to prevent direct skin contact for metal components on tools. The Reveal and Conceal Spot Test Kit available through SmartPractice $^{\text {Tw }}$ (Phoenix, AZ) for either nickel or cobalt includes both a test kit and clear coat barrier product which can be painted on to limit nickel exposure. Hamann et al. showed that enamel spray coatings can be useful in preventing nickel release from keys. In their study, $80 \%$ of the keys tested were positive for nickel release. Treatment with RUST-OLEUM enamel spray has also been shown to effectively limit nickel release [20]. It is important to keep in mind that barrier coatings will require repeat applications over time as they chip and wear off. 
Table 1. Potential patch test allergens of importance in avocational contact dermatitis

\begin{tabular}{|c|c|c|c|c|c|c|c|}
\hline & Percent & Vehicle & G & W & A & C & M \\
\hline 2-Hydroxyethyl methacrylate (HEMA) & 2 & Pet & & + & + & & \\
\hline 4-Chloro-3-cresol (PCMC) & 1 & Pet & + & + & + & & \\
\hline 4-Chloro-3,5-xylenol (PCMX) & 1 & Pet & + & + & + & & \\
\hline 4-Phenylenediamine base & 1 & Pet & + & + & + & + & + \\
\hline 4-Tert-butylphenol formaldehyde resin & 1 & Pet & + & + & + & + & + \\
\hline Abietic acid & 10 & Pet & + & + & + & & + \\
\hline Alpha pinene & 15 & Pet & + & + & & & + \\
\hline Ammonium persulfate & 0.1 & $\mathrm{Aq}$ & & & & + & \\
\hline Aspartame & 0.1 & $\mathrm{Aq}$ & & & & + & \\
\hline Balsam of Peru & 25 & Pet & + & & & + & + \\
\hline Benzyl alcohol & 5 & Pet & + & + & + & + & \\
\hline Benzoic acid & 1 & ethanol & & & & + & \\
\hline Benzoyl peroxide & 1 & Pet & & & & + & \\
\hline Bisphenol A epoxy resin & 1 & Pet & & + & + & & \\
\hline Black rubber mix & 0.6 & Pet & + & + & + & + & + \\
\hline Butylhydroxyanisole (BHA) & 2 & Pet & + & + & + & + & \\
\hline Butylhydroxytoluene (BHT) & 2 & Pet & + & + & + & + & \\
\hline Carba mix & 3 & Pet & + & + & + & + & + \\
\hline Carmine & 0.5 & $\mathrm{Aq}$ & & & & + & \\
\hline Cobalt & 1 & Pet & + & + & + & + & + \\
\hline Cochineal red & 1 & $\mathrm{Aq}$ & & & & + & \\
\hline Cinnamal & 1 & Pet & & & & + & \\
\hline Cinnamyl alcohol & 2 & Pet & & & & + & \\
\hline Colophony & 20 & Pet & + & + & + & & + \\
\hline Compositae mix & 6 & Pet & + & & & & \\
\hline Diallyl disulfide & 1 & Pet & + & & & + & \\
\hline Diazolidinyl urea & 1 & Pet & + & + & + & & \\
\hline DMDM hydantoin & 1 & Pet & + & + & + & & \\
\hline Dodecyl gallate & 0.25 & Pet & & & & + & \\
\hline Ethyl acrylate & 0.1 & Pet & & + & + & & \\
\hline Ethyl cyanoacrylate & 10 & Pet & & + & + & & \\
\hline Eugenol & 2 & Pet & & & & + & \\
\hline Exotic woods & Shavings & & + & + & & & + \\
\hline Formaldehyde & 1 & $\mathrm{Aq}$ & + & + & + & & \\
\hline Imidazolidinyl urea & 2 & Pet & + & + & + & & \\
\hline Iodopropynyl butylcarbamate & 0.2 & Pet & + & + & + & & \\
\hline Isoeugenol & 2 & Pet & & & & + & \\
\hline Lanolin & 50 & Pet & & & & & + \\
\hline Lichen acid mix & 0.3 & Pet & + & & & & \\
\hline Melamine formaldehyde resin & 7 & Pet & & + & & & \\
\hline Menthol & 2 & Pet & & & & + & \\
\hline Mercaptobenzothiazole & 1 & Pet & + & + & + & + & + \\
\hline $\begin{array}{l}\text { Methylchloroisothiazolinone/ } \\
\text { methylisothiazolinone }\end{array}$ & 0.01 & $\mathrm{Aq}$ & + & + & + & & \\
\hline Methyldibromo glutaronitrile (MDBGN) & 0.5 & Pet & + & + & + & & \\
\hline Methylisothiazolinone & 0.2 & $\mathrm{Aq}$ & + & + & + & & \\
\hline Methyl methacrylate & 2 & Pet & & + & + & & \\
\hline Mixed dialkyl thioureas & 1 & Pet & + & + & + & + & + \\
\hline Nickel sulfate hexahydrate & 2.5 & Pet & + & + & + & + & + \\
\hline
\end{tabular}


Table 1. (Continued)

\begin{tabular}{|c|c|c|c|c|c|c|c|}
\hline & Percent & Vehicle & G & W & A & C & M \\
\hline 0ctyl gallate & 0.25 & Pet & & & & + & \\
\hline Paraben mix & 12 & Pet & + & + & + & & \\
\hline Parthenolide & 0.1 & Pet & + & & & & \\
\hline Pectin & 1 & $\mathrm{Aq}$ & & & & + & \\
\hline Phenoxyethanol & 1 & Pet & + & + & + & & \\
\hline Pine tar & 3 & Pet & + & + & & & \\
\hline Potassium dichromate & 0.25 & Pet & + & + & + & + & + \\
\hline Primin & 0.01 & Pet & + & & & & \\
\hline Propolis & 10 & Pet & + & + & & + & + \\
\hline Propylene glycol & 30 & $\mathrm{Aq}$ & + & + & + & & \\
\hline Propyl gallate & 1 & Pet & & & & + & \\
\hline Quaternium-15 & 1 & Pet & + & + & + & & \\
\hline Quinoline yellow & 0.1 & $\mathrm{Aq}$ & & & & + & \\
\hline Saccharin & 0.1 & $\mathrm{Aq}$ & & & & + & \\
\hline Sesquiterpenelactone mix & 0.1 & Pet & + & & & & \\
\hline Shellac & 20 & Ethanol & + & + & + & & + \\
\hline Sodium alginate & 1 & $\mathrm{Aq}$ & & & & + & \\
\hline Sodium benzoate & 5 & Pet & & & & + & \\
\hline Sodium glutamate & 1 & $\mathrm{Aq}$ & & & & + & \\
\hline Sodium nitrate & 2 & $\mathrm{Aq}$ & & & & + & \\
\hline Sorbic acid & 2 & Ethanol & & & & + & \\
\hline Tartrazine & 1 & $\mathrm{Aq}$ & & & & + & \\
\hline Tea tree oil, oxidized & 5 & Pet & + & & & & + \\
\hline Thiuram mix & 1 & Pet & + & + & + & + & + \\
\hline Turpentine peroxide & 0.3 & Pet & + & + & + & & \\
\hline Usnic acid & 0.1 & Pet & + & & & & \\
\hline Vanillin & 10 & Pet & & & & + & \\
\hline Wood tar mix & 12 & Pet & + & + & & & \\
\hline
\end{tabular}

\section{Artists}

Painting and drawing dates back to artifacts from prehistoric humans and the oldest known paintings are reported to be at the Grotte Chauvet in France, claimed by some historians to be about 32,000 years old [21]. Dermatitis is one of the biggest dangers of working with art materials with the hands being the principle site of involvement [22]. Wet clay, plaster, and organic solvents are frequent irritants [23]. Hand eczema and contact dermatitis have been observed significantly more often in the painters [24•].

Paint products include varnishes and paints. Both contain binders (resins), solvents, and additives. The primary difference is that varnishes lack pigment. The most commonly used paints are oil-based, water-based, latex, acrylic, or epoxy [25]. Both varnishes and paints may be a source for irritant or allergic skin disease. The solvent component is the primary source of skin irritation. Over 


\section{Culinarians}

time, there has been a trend toward increasing use of water-based products with fewer solvents.

Allergy may be the result of exposure to the binders (resins), solvents, or additives such as preservatives. Preservatives frequently found in paints include chloracetamide, chlorothalonil, methylchloroisothiazolinone, methylisothiazolinone, benzisothiazolinone, formaldehyde, and thimerosal [26•]. ACD due to paint-associated methylisothiazolinone has been well documented in the recent literature [24•,27-29]. Binders which may be a source of ACD include acrylates, colophony, and epoxy resins [30, 31].

Linseed oil and oil of turpentine are often used by artists to dilute paints and clean brushes and may be a source of skin irritation or allergy [32]. Turpentine oil is a plant-derived substance found not only in lacquers, varnishes, paints, and cleaners but also in liniments and cold remedies including Vicks VapoRub ${ }^{\text {Tu}}$ (Proctor and Gamble, Cincinnati, OH) [33]. Colophony (rosin) is a closely related substance, and cross-reaction can be seen [22].

Management of ICD and ACD in artists should focus on avoiding exposure to the offending agents. Expanded patch testing is useful in identifying sources of ACD.

Table 1 contains a list of potentially relevant allergens to consider in artists with dermatitis. Protection for artists should focus on prevention of direct skin contact with hazardous substances. Protection of the hands can be accomplished by wearing plastic or rubber gloves and is particularly important when working with solvents, acids, or caustic agents. A glove type which is impervious to the material being used should be chosen. Polyvinyl gloves may be suitable for many solvents with the notable exception of those high in ketones such as acetone. Butyl rubber or natural rubber will protect against ketones but not aromatic solvents (e.g., toluol, xylol, and polyester resin), most chlorinated hydrocarbons, acids, or petroleum distillates (namely, mineral spirits, naphtha, and kerosene). For acrylate exposure, a laminate 4-H type glove provides superior protection over rubber and vinyl [31]. Harsh and abrasive soaps should be avoided. Kerosene-based products should not be used to remove paint from the skin because of the defatting action of kerosene. Work areas should be well ventilated to avoid exposure to fumes.

A culinarian or "foodie" is someone with an interest and passion for food. If this interest translates into handling, preparing, or cooking food, then there is a potential for both irritant and allergic contact dermatitis of the hands.

Many of the juices from foods are skin irritants and the resultant hand dermatitis which can be seen is analogous to that seen with any wet work. Some foods are particularly notorious for inducing ICD. Pineapple juice for example contains bromelain which is a proteolytic enzyme and a principle skin irritant [34].

Food may also act as a trigger for ACD or contact urticaria. Garlic and onion for example are members of the family Aliaceae and have been reported to be the most common cause of ACD in caterers and housewives [4]. Diallyl disulfide has been reported to be the primary allergen in garlic. Clinically, the most common presentation is xerotic hyperkeratotic dermatitis of the fingers. Food 
ingredients (e.g., spices) and food additives may also be a source of ACD. Balsam of Peru (also called Myroxylon pereirae) is a complex natural mixture of benzoic acid, benzyl acetate, benzyl benzoate, benzyl cinnamate, cinnamic acid, cinnamic alcohol, cinnamic aldehyde, cinnamyl cinnamate, eugenol, farnesol, isoeugenol, nerolidol, and vanillin. Patients with a positive patch test to balsam of Peru may react strongly to spices such as cinnamon, vanilla, or clove [35].

It is also important to remember that many culinary utensils may contain allergens such as nickel. The handles or grips may also contain black rubber mix or neoprene-related allergens.

Protein contact dermatitis is a unique clinical presentation of dermatitis on the hands and forearms of food handlers. The driving contactants are proteins from food substances such as meat, fish, and cheese. In contrast to the typical $\mathrm{ACD}$, the responsible allergen is felt to be a larger molecular weight protein. Another difference is that these patients have been reported to show a positive scratch test and some patients have been noted to have specific IgE antibodies to the food they handled [36].

The bulk of contact dermatitis associated with food handling involves the hands and forearms, with perioral also being reported. Table 1 contains some of the more common allergens to consider in food enthusiasts with dermatitis. Management should focus on preventing direct skin exposure to irritants and allergens through proper glove use. Vinyl gloves are typically adequate for food handling. Similar to those handling tools, if nickel allergy is a concern, then metal utensils and cooking tools should be tested using the nickel spot test. Sources of high nickel release should be substituted for nickel free (or low release) options.

Music is an art form where the musician or instrumentalist creates, performs, or conducts sounds utilizing a number of materials (e.g., reeds, woods, strings, and metals) in different styles. While many work in the music profession, there are still many others who enjoy this art as a form of recreation.

Dermatoses in musicians have been well documented [37•, 38, 39]. Exposure of the skin and mucosal surfaces to mechanical forces and chemical substances can lead to ICD, ACD, infections, trauma, and even anxietyassociated cutaneous manifestations such as hyperhidrosis. Here, we will focus primarily on ICD and ACD.

Musicians often dedicate hours to both practice and performance. Repetitive localized pressure and friction associated with playing a particular musical instrument may lead to significant cutaneous irritation. The clinical manifestation is often suggestive of the offending instrument. For example, ICD of the submandibular neck has been termed fiddler's neck and suggests the patient plays either the violin or viola. Garrod pads (also known as violinist pads or knuckle pads) are calluses frequently noted on the dorsal proximal interphalangeal joints of the index or middle fingers of violin, viola, or cello players $[37 \bullet]$. 
Chromium, cobalt, colophony (rosin), exotic woods (e.g., Makassar ebony, Cocobolo, African Blackwood, Brazilian and Indian rosewood, ebony wood), nickel, rubber additives, propolis, and lanolin have all been allergens implicated in ACD in musicians. Other commonly noted relevant allergens can be found in Table 1. Metal allergy is particularly important to consider and may be easily overlooked. For example, an allergic form of fiddler's neck may be seen related to nickel bracketing used to attach the chin rest to the instrument. In this case, the dermatitis is often on the supraclavicular neck [40]. ACD to nickel guitar strings has also been reported [41]. Rosin used for stringed instruments may also be a source of ACD [42]. Reports also exist of ACD to the rubber grip component of a violin bow [43], propolis in violin wax [44], and nickel in a school-issued trombone [45].

Management for fiddler's neck can be challenging. A cushion between the chin rest and neck may be of some benefit. Improvement may also be noted with a change in instrument positioning [46]. In cases where nickel bracketing is suspected, an alternative chin rest should be purchased which is free of nickel components such as the Wittner composite hypoallergenic chinrest $^{\text {Tut }}$ (co, location). Similarly, nickel allergic guitarists will need to switch to nickel-free guitar strings. This can be challenging because it has been shown that even stings negative for nickel release on the dimethylglyoxime test can become problematic with use [41]. Patients allergic to colophony should replace their standard rosin with a colophony free alternative such as Super-Sensitive Clarity $\operatorname{Rosin}^{\mathrm{TM}}$ (co, location) which is a synthetic hydrocarbon product.

Table 1 includes patch test allergens of potential importance to the gardener and plant enthusiast. Photopatch testing should also be considered in patients if the distribution of dermatitis is noted to affect the face, upper chest, dorsal forearms and hands with sparing of the upper eyelids, retroauricular, and submental skin. Phytophotodermatitis is a robust irritant reaction driven but light activation of a chemical. Limes, parsnips, figs, celery, dill, and fennel are some of the more commonly noted causes of phytophotodermatitis. A similar distribution can be seen in parthenium dermatitis which is an airborne ACD seen in feverfew sensitivity. Airborne ACD is favored over phytophotodermatitis if involvement of the upper eyelids and retroauricular skin is noted. It is important to note that patch testing with parts of plants can result in irritant reactions difficult to interpret. Testing to unknown plants or plant components should never be performed.

\section{Compliance with Ethical Standards}

\section{Conflict of Interest}

Michael P. Sheehan declares no conflict of interest.

\section{Human and Animal Rights and Informed Consent}

This article does not contain any studies with human or animal subjects performed by any of the authors. 


\section{References and Recommended Reading}

Papers of particular interest, published recently, have been

highlighted as:

- Of importance

1. Svendsen MT, Andersen KE, Thormann H, Paulsen E Contact sensitization to Geranium robertianum L. in a hobby gardener. Contact Dermatitis Online Publication. 2015.

2. Paulsen E, Andersen KE, Hausen BM. An 8-year experience with routine SL mix patch testing supplemented with Compositae mix in Denmark. Contact Dermatitis. 2001;45:29-35.

3. Hausen BM. A 6-years experience with Compositae mix. J Am Contact Dermatitis. 1996;7:94-9.

4. Marks JG, Elsner P, DeLeo V. Contact \& occupational dermatology. St. Louis: Mosby; 2002.

5. Rietschel R, Fowler J. Allergic sensitization to plants. In: Fisher's contact dermatitis. Hamilton, BC Decker Inc; 2008. p. 405-453.

6. Fowler JJ, Marks JJ, Sheretz E, Rietschel R. Prevention of poison ivy and poison oak allergic contact dermatitis by quaternium-18 bentonite. J Am Acad Dermatol. 1995;33:212.

7. Modi GM, Doherty CB, Katta R, Orengo IF. Irritant contact dermatitis from plants. Dermatitis. 2009; 63-78.

8. Ricks M, Vogel P, Elston D, Hivnor C. Purpuric agave dermatitis. J Am Acad Dermatol. 1999;40:356-8.

9. Bruynzeel D. Bulb dermatitis. Dermatological problems in the flower bulb industries. Contact Dermatitis. 1997;37:70-7.

10. Lovell C. Plants and the skin. Oxford and Boston: Blackwell; 1993.

11. Heras-Mendaza F, Casado-Farinas I, Paredes-Gascon M, Conde-Salazar L. Erythema multiforme-like eruption due to an irritant contact dermatitis from a glyphosate pesticide. Contact Dermatitis. 2008;59(1):54-6.

12. Hogan D. Pesticides and other agricultural chemicals. In: Adams RM, editor. Occupational skin disease. Philadelphia: WB Saunders; 1990.

13. Correale C, Marks JJ. Contact dermatitis in a woodworker. Am J Contact Dermatitis. 2002;13:42-4.

14. Woods B, Calnan CD. Toxic woods. Br J Dermatol. 1976;94:1-97.

15. Hausen BM. Contact allergy to woods. Clin Dermatol. 1986;4:65-76.

16. Simpson Strong-Tie, Preservative Treated Wood FAQs. http://www.strongtie.com/productuse/ptwoodfaqs. html. 2012.

17. Finch TM, Prais L, Foulds I. Allergic contact dermatitis from medium-density fibre board containing melamine-formaldehyde resin. Contact Dermatitis. 1999; 41:291.

18. Lidén C, Röndell E, Skare L, Nalbanti A. Nickel release from tools on the Swedish market. Contact Dermatitis. 1998;39:127-31.
19. Thyssen J, Menné T, Johan J. Identification of metallic items that caused nickel dermatitis in Danish patients. Contact Dermatitis. 2010;63:151-6.

20. Hamann D, Scheman A, Jacob S. Nickel exposure from keys: alternatives for protection and prevention. Dermatitis. 2013;24(4):186-9.

21. History of Art, Paintings and Artists. Art History Resources. http://www.historyofpaintings.com/.

22. Barchino-Ortiz L, Cabeza-Martinez R, Leis-Dosil V, Lazaro-Ochaita P. Allergic contact hobby dermatitis from turpentine. Allergol Immunopathol. 2008;36(2):117-9.

23. Rycroft R, Menne T, Frosch P, Lepoittevin J. Occupational contact dermatitis. In: Textbook of contact dermatitis. Verlag Berlin Heidelberg New York: Springer; 2001. p. 557-576.

24. Mose A, Lundov M, Zachariae C, Menne T, Veien N, Laurberg G, et al. Occupational contact dermatitis in painters: an analysis of patch test data from the Danish Contact Dermatitis Group. Contact Dermatitis. 2012;67(5):293-7.

This study reviewed the patch test results of 219 painters and noted an increased risk of hand eczema over matched controls. Isothiazolinones were noted to be the most frequent sensitizers.

25. Valsecchi R, Leghissa P, Piazzolla S. Occupational contact dermatitis from paints. Clin Dermatol. 1992;10:185-8.

26. Castanedo-Tardana MP, Zug KA. Methylisothiazolinone. Dermatitis. 2013;24(1):2-6.

This paper is an excellent review of methylisothazolinone.

27. Lundov M, Friis U, Menne T, Johansen J. Methylisothiazolinone in paint forces a patient out of her apartment. Contact Dermatitis. 2013;69(4):252-3.

28. Madsen J, Andersen K. Further evidence of the methylisothiazolinone epidemic. Contact Dermatitis. 2014;70(4):246-7.

29. Tokunaga M, Fujii H, Okada K, Kagemoto Y, Nomura $\mathrm{T}$, Tanioka $\mathrm{M}$, et al. Occupational airborne contact dermatitis by isothiazolinones contained in wall paint products. Allergol Int. 2013;62(3):395-7.

30. Conde-Salazar L, Vargas I, Tévar E, Barchino L, Heras F. Sensitization to acrylates in varnishes. Dermatitis. 2007;18(1):45-8.

31. Rietschel RL, Fowler JF. Occupational dermatitis. In: Fisher's contact dermatitis. Hamilton, BC Decker Inc; 2008. p. 494-496.

32. Laube S, Tan B. Contact dermatitis from turpentine in a painter. Contact Dermatitis. 2004;51(1):41-2.

33. Noiles K, Pratt M. Contact dermatitis to Vicks VapoRub. Dermatitis. 2010;21(3):167-9. 
34. Hand dermatitis due to contactants. In: Fisher's contact dermatitis. Hamilton, BC Decker Inc; 2008. p. 319338.

35. Scheman A, Rakowski E, Chou V, Chhatriwala A, Ross J, Jacob S. Balsam of Peru: past and future. Dermatitis. 2013;24(4):153-60.

36. Cheryl L, Warshaw E. Protein contact dermatitis: allergens, pathogenesis, and management. Dermatitis. 2008; 241-251.

37. Vine K, DeLeo V. Dermatologic manifestations of musicians: a case report and review of skin conditions in musicians. Cutis. 2011;87(3):117-21.

Excellent expanded review on the dermatologic manifestations seen in musicians.

38. Adams R. Skin conditions of musicians. Cutis. 2000;65:37-8.

39. Gambichler T, Uzun A, Boms S, Altmeyer P, Altenmüller E. Skin conditions in instrumental musicians: a self-reported survey. Contact Dermatitis. 2008;58:217-22.

40. Caero J, Cohen P. Fiddler's neck: chin rest-associated irritant contact dermatitis and allergic contact dermatitis in a violin player. Dermatol Online J. 2012;18(9):10.

41. Friis $U$, Menne T, Jellesen M, Moller P, Verdingovas $\mathrm{V}$, Jensen $\mathrm{T}$, et al. Allergic nickel dermatitis caused by playing the guitar: case report and assessment of nickel release from guitar strings. Contact Dermatitis. 2012;67(2):101-3.

42. Vandebuerie L, Aerts C, Goossens A. Allergic contact dermatitis resulting from multiple colophoniumrelated allergen sources. Contact Dermatitis. 2014;70(2):117-9.

43. Herro E, Friedlander S, Jacob S. Violin bow-associated rubber allergy in a child. Dermatitis. 2011;22(4):2234.

44. Lieberman H, Fogelman J, Ramsay D, Cohen D. Allergic contact dermatitis to propolis in a violin maker. J Am Acad Dermatol. 2002;46:S30-1.

45. Jacob S, Herro E. School-issued musical instruments: a significant source of nickel exposure. Dermatitis. 2010;21(6):332-3.

46. Stern J. The edema of fiddler's neck. J Am Acad Dermatol. 1979;1:538-40. 